\title{
Michel Murat, Le Vers libre
}

\section{Fabio Scotto}

\section{(2) OpenEdition \\ 1 Journals}

\section{Edizione digitale}

URL: http://journals.openedition.org/studifrancesi/7341

DOI: ERREUR PDO dans /localdata/www-bin/Core/Core/Db/Db.class.php L.34 : SQLSTATE[HYO00]

[2006] MySQL server has gone away

ISSN: 2421-5856

\section{Editore}

Rosenberg \& Sellier

\section{Edizione cartacea}

Data di pubblicazione: 1 avril 2010

Paginazione: 181-182

ISSN: 0039-2944

\section{Notizia bibliografica digitale}

Fabio Scotto, «Michel Murat, Le Vers libre», Studi Francesi [Online], 160 (LIV | I) | 2010, online dal 30

novembre 2015, consultato il 07 janvier 2021. URL: http://journals.openedition.org/studifrancesi/7341 ; DOI: https://doi.org/ERREUR PDO dans /localdata/www-bin/Core/Core/Db/Db.class.php L.34 : SQLSTATE[HYO00] [2006] MySQL server has gone away

Questo documento è stato generato automaticamente il 7 janvier 2021.

\section{(c) $($ ) $(9)$}

Studi Francesi è distribuita con Licenza Creative Commons Attribuzione - Non commerciale - Non opere derivate 4.0 Internazionale. 


\title{
Michel Murat, Le Vers libre
}

\author{
Fabio Scotto
}

\section{NOTIZIA}

MICHEL MURAT, Le Vers libre, Paris, Champion, 2008 («Littérature de notre siècle», 36), pp.

329.

1 Questo studio affronta una questione poetologica fondamentale e ha il merito di farlo da una prospettiva storica, non solo estetica, stabilendo un utile dialogo con altre recenti teorizzazioni ineludibili. Il periodo preso in considerazione è quello della «crise de vers» che va dal 1886, segnato dalla pubblicazione delle Illuminations ne «La Vogue»e dai primi saggi di G. Kahn, J. Laforgue e J. Moréas, fino alla standardizzazione del verso libero cui s'approda con l'Apollinaire di Ondes e il Cendrars dei Dix-neuf poèmes élastiques, tra Simbolismo e Modernismo (pp. 9-12). Nella prima parte, «Histoire et structure», l'A. colloca il verso libero - struttura paradossale in quanto libero riguardo al computo sillabico, ma pur sempre determinato in quanto verso -, nell'alveo simbolista, al quale pur non risulta del tutto ascrivibile, e lo ripensa alla luce di alcuni contributi novecenteschi, da H. Friedrich a J. Roubaud e H. Meschonnic qui incontrando lo scoglio del rapporto verso-prosa: nella ritmica di Meschonnic, la letteratura tutta si colloca nel poème al di là di ogni distinzione fra poesia e prosa, come nella Bibbia, mentre in Roubaud (La Vieillesse d'Alexandre, 1978), nel solco del quale, pur riconoscendo la pertinenza di varie argomentazioni meschonnicchiane, Murat si situa, sono la metricità e il computo sillabico a prevalere, nel vers-librisme egli vedendo l'«antialexandrin» che del verso accentua la crisi per penuria di forma.

2 Rivalutando anche grazie ai contributi di A. Boschetti e L. Jenny l'impulso avanguardistico modernista che il surrealismo avrebbe almeno in parte occultato, Murat rivolge la sua attenzione alla forma standard definendo il verso libero come «un segment de longueur variable» la cui segmentazione è contrassegnata dalla «convention typographique qui est le passage à la ligne» (p. 34), poi studiandone la scansione sillabica, la ritmica relativa e la prosodemia relazionale e tonale con le sue 
polarità clitiche. Provenienza estera e gioventù dei poeti del verso libero sono elementi non trascurabili nella sua elaborazione (p. 68). Nello studiare la forma rimbaldiana delle Illuminations, l'A. ne mostra la sostanziale estraneità al verso libero, per il prevalere della poesia in prosa, salvo le poche eccezioni di testi quali Enfance III, Départ e altri. Nell'ultimo Laforgue entra molto in gioco il ricorso a metri misti rinforzati da parallelismi, in G. Kahn si tratta meno della nuova forma che non di una forma che consente di scrivere attraverso essa versi nuovi in quella forma (pp. 90-91), con un'intuizione ritmica già contemporanea se leggiamo che «le vers libre [...] doit exister en lui-même par des allitérations de voyelles et de consonnes parentes» (p. 98). La seconda parte, «La Polymorphie», fornisce un'ampia gamma di esempi da Viélé-Griffin, R. De Souza, Verhaeren, Saint-John Perse per mostrare la varietà delle tipologie versificatorie, rimico-strofiche e d'impaginazione che nell'allineamento al margine sinistro, nel ricorso alla maiuscola iniziale, nelle figure di variazione e di rinforzo, come nelle dinamiche di spazializzazione (da Mallarmé a Reverdy) disegnano una fisionomia eteroclita e vivace di respirazioni testuali. La terza parte, «Styles», dedica pagine acute e vibranti a V. Larbaud, P. Claudel, Ch. Péguy e A. Breton, il quale contiene il lirismo grazie al vers-librisme (p. 298), pur l'A. ribadendo nell'«Épilogue» il carattere epigonistico di molte forme attuali dell'uso dello strumento tecnico al centro della sua ricca e stimolante analisi. 